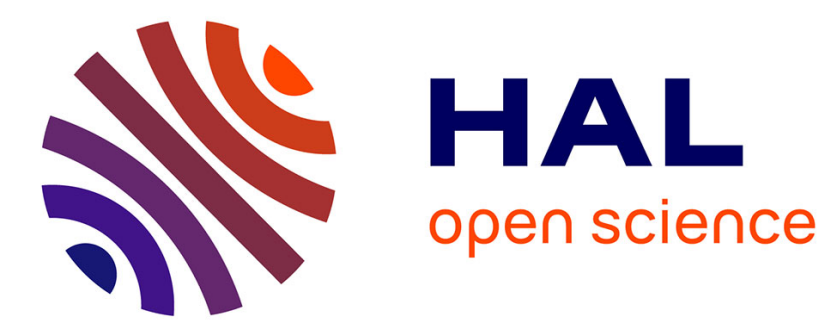

\title{
STM Study on Surface Relief, Ultra-Fine Structure and Transformation Mechanism of Bainite in Steels
}

\author{
H.-S. Fang, Z.-G. Yang, J.-J. Wang, Y.-K. Zheng
}

\section{To cite this version:}

H.-S. Fang, Z.-G. Yang, J.-J. Wang, Y.-K. Zheng. STM Study on Surface Relief, Ultra-Fine Structure and Transformation Mechanism of Bainite in Steels. Journal de Physique IV Proceedings, 1995, 05 (C8), pp.C8-521-C8-526. 10.1051/jp4:1995880 . jpa-00254129

\section{HAL Id: jpa-00254129 https://hal.science/jpa-00254129}

Submitted on 1 Jan 1995

HAL is a multi-disciplinary open access archive for the deposit and dissemination of scientific research documents, whether they are published or not. The documents may come from teaching and research institutions in France or abroad, or from public or private research centers.
L'archive ouverte pluridisciplinaire HAL, est destinée au dépôt et à la diffusion de documents scientifiques de niveau recherche, publiés ou non, émanant des établissements d'enseignement et de recherche français ou étrangers, des laboratoires publics ou privés. 


\title{
STM Study on Surface Relief, Ultra-Fine Structure and Transformation Mechanism of Bainite in Steels*
}

\author{
H.-S. Fang, Z.-G. Yang, J.-J. Wang and Y.-K. Zheng \\ Dept. of Materials Science and Engineering, Tsinghua University, Beijing 100084, China
}

The surface reliefs accompanying lower bainite transformation in steels have been studied by scanning tunneling microscopy (STM). With the exclusive vertical resolution of STM, we observed that the surface relief associated with bainite is a group of surface reliefs related to subplates, subunits and sub-subunits. From the bainite plate to the sub-subunit in it, the reliefs are in a tent shape, not of invariant plane strain (IPS) type. The fine structure of bainite in a steel has also been shown by STM and TEM that bainite plate is composed of subplates, subunits and subsubunits. On the basis of the fine structure inside a bainitic ferrite plate observed under STM, sympathetic-ledgewise mechanism of bainite formation is proposed.

\section{INTRODUCTION}

Since the early work on the morphology of bainite in steel by Robertson ${ }^{[1]}$ and by Davenport and Bain $^{[2]}$, considerable disagreement ${ }^{[3]}$ has been developed about bainite formation mechanism. One of the important experimental evidence supporting shear mechanism is the work of Ko and Cottrell ${ }^{[4]}$ and $\mathrm{Ko}^{[5]}$ alone, which show that bainite and Widmanstatten ferrite in a hypereutectoid steel grow slowly but simultaneously produce martensite-like upheaval on the free surface, but that grain boundary ferrite allotriomorphs do not, and deduced that bainite forms by shear as martensite. But many works ${ }^{[6-9]}$ found that the shape of bainite surface relief is often "tent-like", and of martensite is of IPS type.The bainite seems most possible to form in a way different from martensite. It is of no doubt that the nature of surface reliefs remains as a key point in studying bainitic transformation.

Up to now, almost all the research works concerning surface relief have been done with optical differential interference microscope. It is not enough to observe more details of the surface distcrtion due to the limitation of the resolution. As a newly developed surface analysis microscopy by Binnig and Rohrer ten years ago ${ }^{[10]}$, Scanning tunneling microscopy (STM) has very high vertical resolution as to sub-angstrom level, ca. $0.01 \mathrm{~nm}$, in addition to high lateral resolution of $0.1 \mathrm{~nm}$, and proved itself a powerful analytical tool to observe the fine structure of bainite ${ }^{[11]}$. In the present paper, STM is employed to study fine structure of surface relief accompanying bainite transformation in steels.

\section{EXPERIMENTAL PROCEDURE}

The alloy contents and heat treating details of the experimental alloys are given in Table 1 . In order to study surface relief phenomena associated with bainite, the prepolished specimen of S3 was austempered while sealed in an evacuated silica tube, and to be studied by STM without etching.

The surface of the as-prepared specimen was examined with STM. STM was performed in air at ambient conditions under a constant tunneling current mode. The detailed procedures for STM experimental have been described elsewhere.

\footnotetext{
* This work has been supported by National Natural Science Foundation of P.R.China.
} 
Table 1. Alloy compositions and heat treatment details of experimental alloys

\begin{tabular}{|c|l|l|}
\hline Labels & \multicolumn{1}{|c|}{ Compositions } & \multicolumn{1}{|c|}{ Heat treatment } \\
\hline S1 & $\mathrm{Fe}-1.0 \mathrm{C}-2.0 \mathrm{Si}-4.0 \mathrm{Cr}$ & $1373 \mathrm{~K} \times 30 \mathrm{mins}+573 \mathrm{~K} \times 30 \mathrm{mins}$. \\
\hline S2 & $\mathrm{Fe}-0.5 \mathrm{C}-1.4 \mathrm{Si}-3.8 \mathrm{Cr}$ & $1373 \mathrm{~K} \times 10 \mathrm{mins}+608 \mathrm{~K} \times 15 \mathrm{mins}$ \\
\hline S3 & $\mathrm{Fe}-2.2 \mathrm{C}-12.2 \mathrm{Cr}$ & $1373 \mathrm{~K} \times 10 \mathrm{mins}+573 \mathrm{~K} \times 30 \mathrm{hrs}$. \\
\hline
\end{tabular}

\section{A. Optical morphology}

III. RESULTS AND DISCUSSION

The optical microstructure of the steel S1 re-acted for 30 hrs at $573 \mathrm{~K}$ is shown in Fig. 1(a), which is composed only by bainite plates(see arrow B) and austenite matrix owing to the additional silicon and less carbon content. S2 has the similiar microstructures with S1. The optical microstructure of the alloy S3 re-acted for $30 \mathrm{hr}$ at $573 \mathrm{~K}$ is shown in Fig. 1(b). It consists of typical lower bainite plates(dark etched as arrow $\mathrm{B}$ ), equiaxial $(\mathrm{CrFe})_{7} \mathrm{C}_{3}$ carbide (indicated by $\mathrm{A}$ ), and the remaining austenite matrix. The average carbon content of austenite and bainite is approximately $1.2 \mathrm{wt} . \%$, owing to the presence of $(\mathrm{CrFe})_{7} \mathrm{C}_{3}$ carbide ${ }^{122}$.

(a)

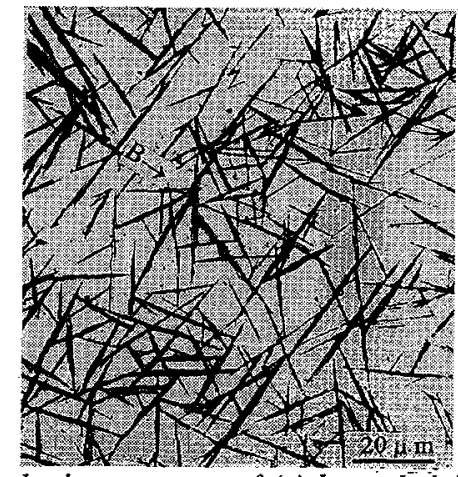

(b)

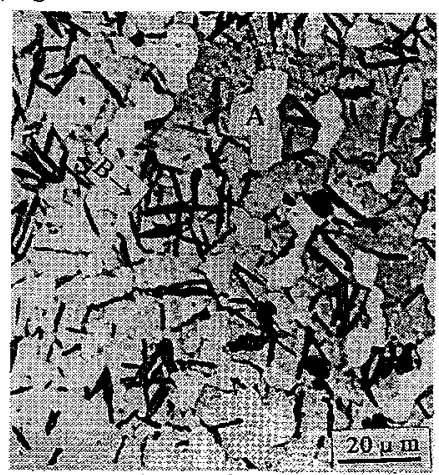

Fig. 1 Optical microstructure of (a) lower bainite in steel SI reacted at $573 \mathrm{~K}$ for 30 mins, (b)lowr bainite in steel $S 3$ reacted at $573 K$ for $30 \mathrm{hrs}$. (all etched)

\section{B. Ultra-fine structures of bainite}

$\dot{U}$ p to now, bainitic plates are considered as aggregates of sheaves ${ }^{[13]}$, i.e., subplates, which consist of subunits ${ }^{[14]}$. However, inner structure of subunits has seldom been reported. In addition to TEM, STM has also been carried out to study the microstructure of steel S1. Fig. 2 are STM images of bainite in the steel S1. There are two plates shaped precipitates in Fig. 2(a), indicated by long arrow A and B, with their tips in conjunct with each other. Clearly, plate A and B are composed of several subplates, and the subplates are composed of subunits, which is arrayed parallel, but of different size. The magnified image of subunits in the up-right part of plate $A$ in Fig. 2(a) is presented in Fig. 2(b),(c) and (d). It can be seen clearly that there are sub-subunits indicated by $1,2,3$ and 4 inside a subunit. Sub-subunits are $20-40 \mathrm{~nm}$ in width, and 0.2-0.3 $\mu \mathrm{m}$ in length.

To confirm the existence of sub-subunit, TEM work was made in the steel S1. Fig. 3(a) is a TEM dark field image of the bainite, imaged by $(\overline{1} 12) \alpha$, and shows a complicated structure, that is, the bainite is actually a sheaf, and the sheaf is composed many subunits in different sizes. It is clear that the subunits also contain fine structure, i.e. sub-subunits as observed under STM, but is not so clearly shown by TEM. Fig. 3(b) is the corresponding indexing result of the selected area diffraction pattern.

Sub-subunit is not the smallest unit, we also find sub-sub-subunits in bainte by STM. Fig. 4 presents another structure of bainite in $S 2$, which has a similiar optical microstructure of bainte in $\mathrm{S} 1$. A bainite plate is composed of many parallel subunits, indicated by A in Fig. 4(a), which are arrayed parallel to one another, but of irregular shape and having different sizes. If we focus on subunit $A$ and decrease the scan size, we can get the locally magnified structure of Fig. 4(a), as presented in Fig. 4(b). It shows that there are sub-subunits indicated by B, C inside subunit A. If decrease the scan size furthermore, we can get the image of Fig. 4(c). In Fig. 4(c) that there are sub-sub-subunits inside sub-subunit $C$, as indicated by 1,2 and 3 . Apparently, the observed structure of bainite by STM is different from the classical concept of a plate shaped precipitate. 
(a)
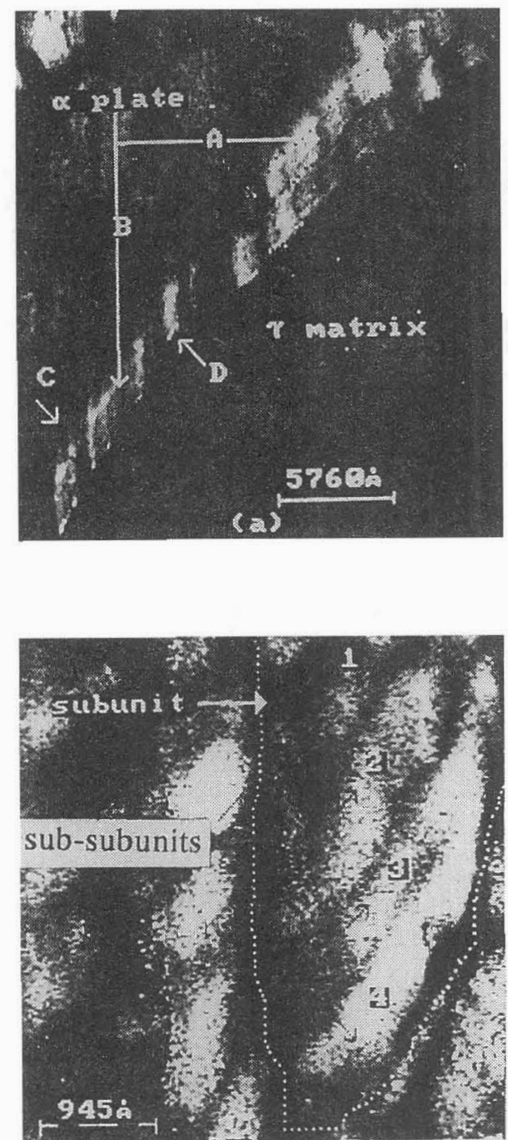

(b)
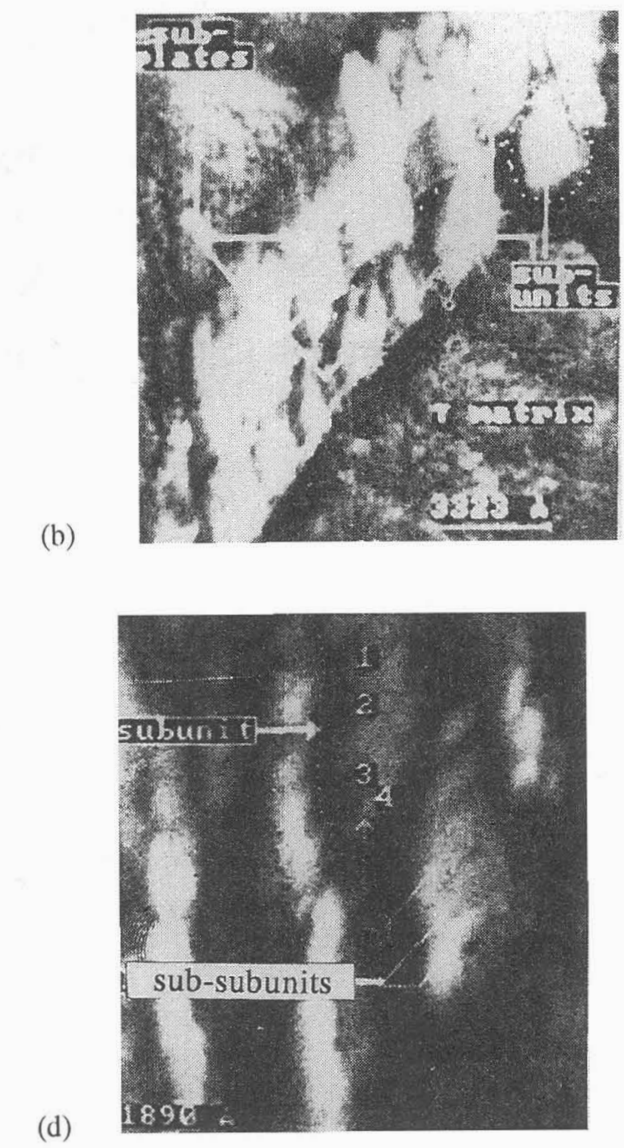

(c)

(d)

Fig. 2 (a)The STM image of bainite in steel S1, (b), (c), (d) higher magnification of part of bainite plate in (a) showing sub-subunits.

(a)

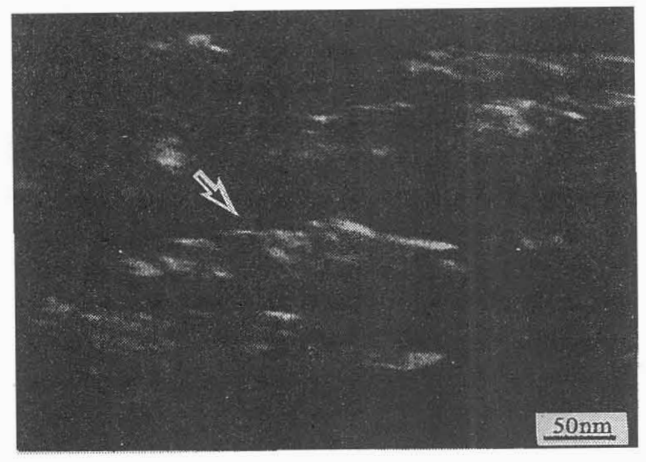

(b)

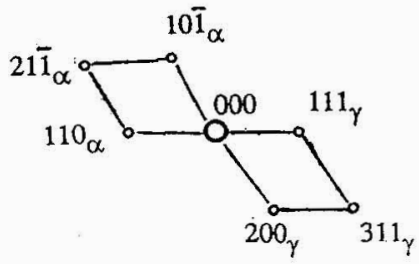

Fig. 3 TEM image of. steel SI reacted at 573K for 2 hrs (a) (112) a DF image (b) indexing results of select area diffraction pattern 


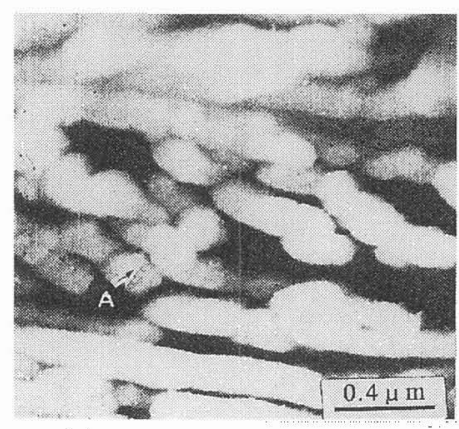

(a)

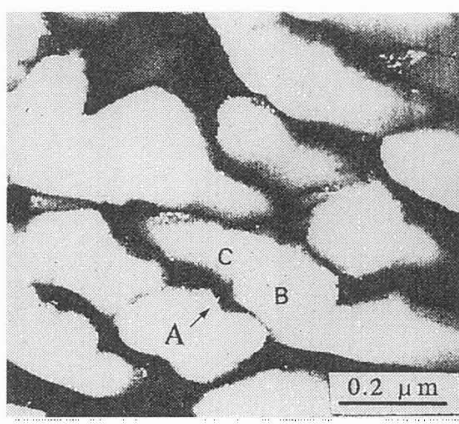

(u)

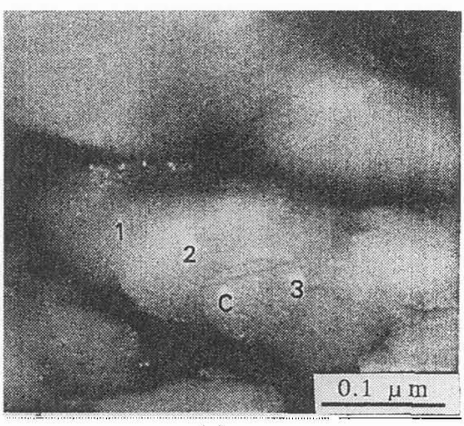

(c)

Fig. 4 Top view of ultra-fine structure of bainite in steel S2 shown by STM; (a) subplates and subunits, (b) sub-subunits, and (c) sub-sub-subunits.

\section{Surface relief accompanying lower bainite}

The three-dimensional (3-D) morphology of a bainitic sheaf in the isothermally heat treated steel S3 is shown in Fig. 5(a). The topographic gray scale image of Fig. 5(a) is presented in Fig. 5(b) after being filter processed. As is indicated by dotted lines in Fig. 5(b), the microstructure of the bainitic plate is not homogeneous. Locally magnified images of Fig. 5(a) is presented in Fig. 5(c). The surface profile along line AA in Fig. 5(a) shows the integral morphology of bainitic relief which is obviously tent-like, i.e., not an IPS type, as shown in Fig. 5(d). The height of the tent shaped relief is ca. $0.2 \mu \mathrm{m}$. Fig. 5(a) through (c), as well as the profile along line BB (Fig. 5(a)) shown in Fig. 5(e), show that the bainitic relief has a much finer structure. The smaller tents can also be seen in Fig. 5(c). From Fig. 5(c) we can seen that a sub-subunit is composed of sub-subsubunits. The surface profile along line $\overline{A A}$ in Fig. 5(c) is presented in Fig. 5(f), which shows that the relief corresponding to a sub-sub-subunit is also tent shaped. This profile is not contused by the too close proximity of other sub-sub-subunits and thus appears to represent the true shape of the surface relief. Fig. $5(\mathrm{~g})$ shows the surface protile along the $\overline{C C}$ line in Fig. 5(c) showing the nature of two adjacent intersecting surface relief lines corresponding to a sub-subunit and sub-subsubunit. The sub-subunit and sub-sub-subunit are referred as "ultra-fine structure" here, which is discovered only by STM (but not by TEM), in contrast to the "fine structure" by TEM and "microstructure" by optical microscopy.

Consequently, the bainitic relief is composed of a group of parallel small surface reliefs corresponding to subplates. The surface relief of a bainite plate is $0.10-0.25 \mu \mathrm{m}$ in width and contains fine structures. The height of the bainite plate relief is $c a .0 .15 \mu \mathrm{m}$, and the height of subplate reliefs is $0.01 \mu \mathrm{m}$, near the resolution limit of optical microscopy. The height of subunit reliefs is $c a .5 \mathrm{~nm}$ and beyond the resolution ability of optical microscopy, but can only be seen by STM. The subunits can be divided into sub-subunit in the longitudinal direction; their heights are ca. $2 \mathrm{~nm}$. A sub-subunit can be decomposed into sub-sub-subunits. The relief height of sub-subsubunits is $c a .0 .3 \mathrm{~nm}$. It can thus be seen that all the reliefs, no matter what levels of substructures, are tent shaped. But it should be pointed out that the reliefs corresponding to bainitic sheaves, subplates, subunits, or sub-subunits are actually formed by combination of many smaller reliefs from sub-sub-subunits. Only the relief accompanying the smallest structural unit, i.e., sub-subsubunits, of bainite can delineate the formation mechanism of bainite.

So far, we can define the surface relief accompanying bainite as a group of reliefs related to the complex fine structure of bainite, i.e., subplates, subunits and sub-subunits (see the schematic model as Fig. 5(h)). So it is of non-IPS type. Furthermore, the surface reliefs accompanying subplate, subunit, sub-subunit and sub-sub-subunit are still of non-IPS type, as indicted by Fig. 5(d) through $5(\mathrm{~g})$, the surface reliefs are all tent-like. According to the phenomenological theory of martensite crystallography, we can deduced that the bainite is impossible to transform in shear mechanism. 


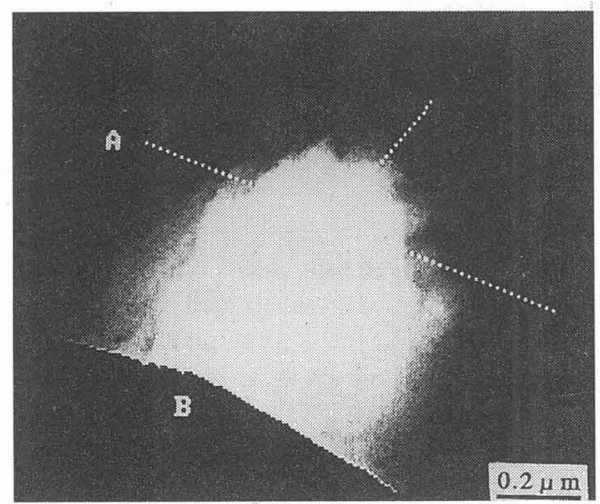

(a)

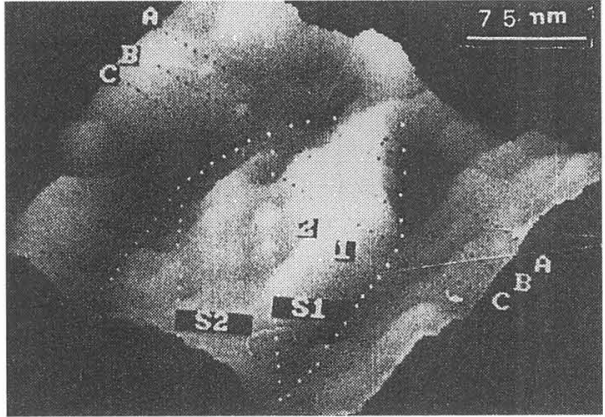

(c)

(e)
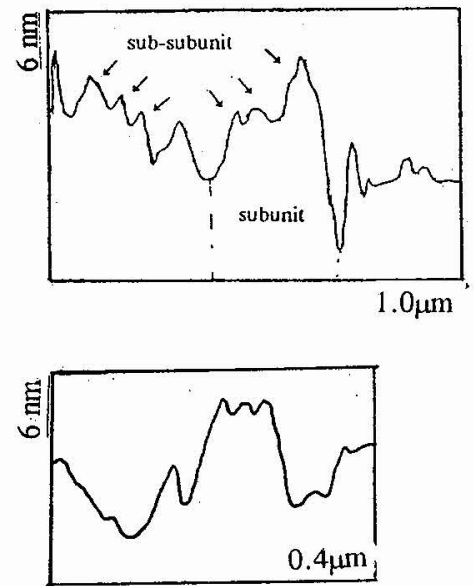

(g)

(f)

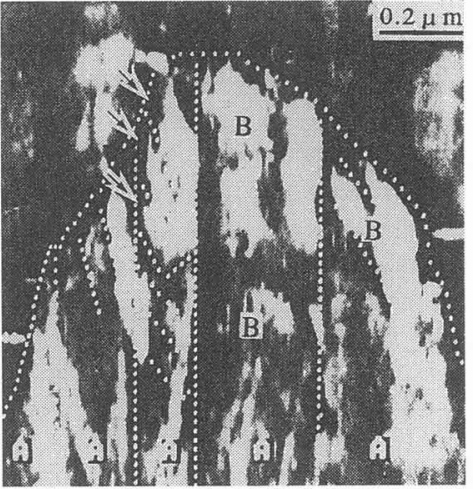

(b)

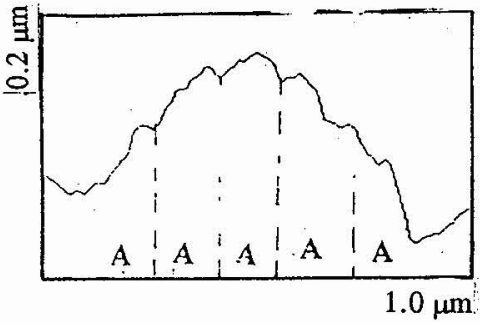

(d)
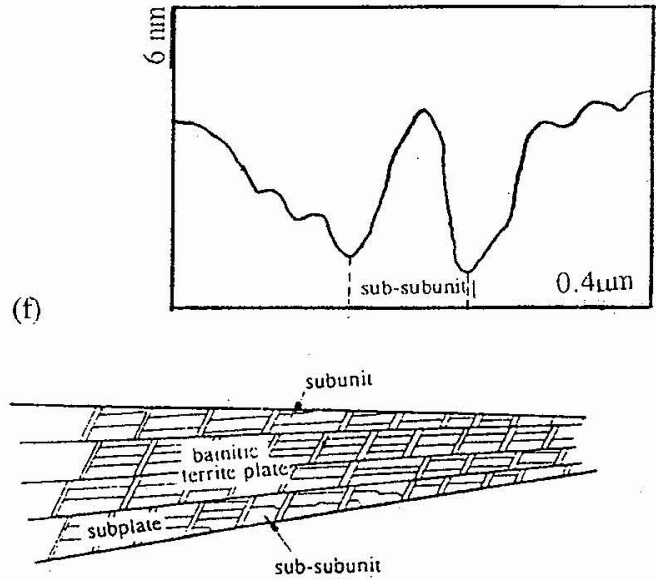

(h)

Fig. 5 Surface relief accompanying lower bainite in S3 shown by STM; (a) 3-D topography, (b) gray scale image, (c) locally magnified result of $(a) ;(d),(e),(f)$ and $(g)$ are profiles along line $\overline{A A}$ in $(a)$, line $\overline{B B}$ in $(a)$, line $\overline{A A}$ in (c) and line $\overline{C C}$ in (c), respectively,. (h) the schematic model of bainite. 
It should be noted that Fig. 2 and Fig. 4 are the result of bainite revealed by $4 \%$ nital under STM, and the boundary of sub-subunits may be explained in other ways, such as recovery of dislocation or/and other line defects in bainite ferrite. If the boundary between sub-subunits comes from the recovery of dislocation, it should be revealed only after etched, however, the work in this paper also deal with bainite without etching and found surface reliefs related to sub-subunits in Fig. 5. This confirms the exact existence of sub-subunits.

\section{Sympathetic-ledgewise mechanism of bainite transformation}

The complex bainite structures, including subplate, subunit, sub-subunit and sub-subsubunit indicate a new transformation mechanism of bainite, i.e., sympathetic-ledgewise mechanism. Usually, sympathetic nucleation is defined as "the nucleation of a precipitate crystal at the interphase boundary of another crystal of the same phase when both crystals differ in composition from that of the matrix from nucleation throughout growth" ${ }^{[3]}$. The sympathetic-ledgewise mechanism means that the bainite grows through migration of growth ledges on the broad face, and when the growth is ceased, sympathetic nucleation occurred to form new nucleus. So through continuous sympathetic nucleation, sub-subunit, subunit, subplate, and, bainitic plate are formed.

The formation of original bainite nucleus is an atom-diffusion process, $\alpha$ and $\gamma$ are usually different in compositions. With the thickening of $\alpha$, carbon and substitute elements will pile-up in the $\alpha: \gamma$ boundary. At this time the growth of $\alpha$ is completely controlled by volume diffusion of atoms inside the $\gamma$ matrix. With increasing diffusion time, a large amount of carbon atoms will be pushed into the $\gamma$ matrix at the migrating ledge, and the composition gradient of the carbon in boundary decreases with increasing diffusive growth, and thus the migration rate of the ledge also decreases, finally to zero. Then the formation of new nucleus happens. The energy of nucleation comes from: nucleated at the initial $\alpha: \gamma$ boundary in order to take the advantage of consuming boundary energy as much as possible; exhausting strain energy of austenite near the boundary; and nucleated in some area with less carbon enrichment to decrease bulk free energy. So sympathetic nucleation could occur in everywhere near the growth ledge, by face-to-face, edge-to-face or edge-to-edge, which results in a multi-layer structure, as described in Fig. 5(h).

\section{CONCLUSIONS}

1. Bainite in steels was found by STM to be of complicated structure, e.g., a plate is composed of subplates, subplates are composed of subunits, subunits are composed of sub-subunits, and subsubunits are composed of sub-sub-subunits.

2. STM studies indicate that surface relief accompanying lower bainite is "tent-shaped", not of IPS type, which implying bainite can not form by shear mechanism as martensite.

3. Surface relief of lower bainite is indeed a group of small reliefs related with subplates, subunits, sub-subunits and sub-sub-subunits. Their heights are $c a .10 \mathrm{~nm}, 5 \mathrm{~nm}, 2 \mathrm{~nm}$ and $0.3 \mathrm{~nm}$, respectively.

4. The formation of lower bainite has been interpreted through sympathetic-ledgewise mechanism.

[1] J.M.Robertson: ISIJ,1929, vol.119, p. 391

\section{REFERENCES}

[2] E.S. Davenport, E.C.Bain: Trans. AIME,1930, vol. 90, p.117

[3] H.I.Aaronson, Symposium on Plase Transformations' 93, Nov. 1993, Beijing,China

[4] T. Ko, S. A. Cottrell: ISIJ, 1952, vol. 172, p:307

[5] T. Ko: ISU., 1953, vol. 175, p.16

[6] H.I. Aaronson: Scripta Metall., 1980,vol. 14, p.825

[7] H.J.Lee, H.I.Aaronson: Acta Metall.,988, vol. 36, p.787

[8] U.Dahmen: Scripta Metall.,1987, vol. 21, p.1027

[9] H.I.Aarouson: Phase Transf.,ASM,Met.Park, OH,1970, p.313

[10] G.Binnig,H.Rohrer,C.Gerber: Phys.Rev.Let.,1982, vol. 49, p.57

[11] H.S.Fang,J.J.Wang,Y:K.Zheng, Z.G.Yang:STM in Mat. Sci.,Sci.Press,Beijing, 1993, p.66(in Chinese)

[12] H.S.Fang,J.J.Wang, Y.K.Zheng, Z.G. Yang:Acta Metall.Sinica, 1993, vol. 29A, p.445(in Chinese)

[13] H.I.Aaronson, C. Wells: Trans. AIME,1956, vol. 206, p. 1216

[14] R.F.Hehemann: Phase Transformation,ASM, 1970, p.397 